\title{
Toward Ultimate Care for Graves' Hyperthyroidism
}

\author{
Fereidoun Azizi ${ }^{1}{ }^{*}$ and Hengameh $\mathrm{Abdi}^{1}$ \\ ${ }^{1}$ Endocrine Research Center, Research Institute for Endocrine Sciences, Shahid Beheshti University of Medical Sciences, Tehran, Iran \\ "Corresponding author: Endocrine Research Center, Research Institute for Endocrine Sciences, Shahid Beheshti University of Medical Sciences, Tehran, Iran. Email: \\ azizi@endocrine.ac.ir \\ Received 2019 September 21; Accepted 2019 October 12.
}

Keywords: Hyperthyroidism, Graves, Antithyroid Drug

Nowadays, throughout the world a majority of patients with Graves' hyperthyroidism are treated with antithyroid drugs (ATDs) (1, 2); however, hyperthyroidism recurs in almost $20 \%-70 \%$ of patients following discontinuation of medical treatment (3). The 2016 American Thyroid Association (3) and 2018 European Thyroid Association (4) guidelines have recommended that patients with recurrence of Graves' hyperthyroidism, after the conventional 12 to 18 -month ATD therapy, should undergo an ablation treatment with radioactive iodine (RAI) or thyroidectomy. Moreover, findings of the 2010 Cochrane review (5) underscoring the limited number of trials comparing ATD treatment $<12$ months versus $>12$ months, led to inclusion of continued long-term ATD therapy based only on patient preference being suggested in these guidelines $(3,4)$. Unfortunately, after both RAI and thyroidectomy, the hyperthyroid patient may often be faced by another disease i.e. hypothyroidism; in addition, RAI-treated patients may have a higher risk of death from solid cancers (6) and patients undergoing thyroidectomy may be prone to several morbidities and complications (3).

Over the past 15 years, a few studies (7-11) and two systematic review/meta-analyses $(12,13)$ have shown that longterm ATD treatment of patients with Graves' hyperthyroidism, viz. with methimazole, is effective in the maintenance of euthyroidism for up to 15 years without additional adverse effects. Efficacy and safety of long-term ATD therapy have overall been documented in over 1600 children, adolescents, and adult patients with Graves' disease (7-11,14-16).

The highest remission rate of Graves' hyperthyroidism occurs after long-term methimazole therapy; it has recently been reported that $84 \%$ of adults and $88 \%$ of adolescents with Graves' disease attain cured 4 years after discontinuation of methimazole $(17,18)$.

We believe that recommendations for conventional
ATD treatment for 12 - 18 months should be revised. Considering the effectiveness of long-term medical therapy along with a rarity of side effects with methimazole, physicians should treat patients with Graves' hyperthyroidism for a minimum of 5 years, and if needed for many years to come. Further research should focus on the $16 \%$ of Graves' patients who have a relapse of hyperthyroidism after discontinuation of long-term ATD therapy for detection of any factors related to the relapse.

\section{Footnotes}

Conflict of Interests: I declare no competing interests Funding/Support: There is no related financial support.

\section{References}

1. Brito JP, Schilz S, Singh Ospina N, Rodriguez-Gutierrez R, Maraka $S$, Sangaralingham LR, et al. Antithyroid drugs-the most common treatment for Graves' disease in the United States: A nationwide population-based study. Thyroid. 2016;26(8):1144-5. doi: 10.1089/thy.2016.0222. [PubMed: 27267495].

2. Bartalena L, Burch HB, Burman KD, Kahaly GJ. A 2013 European survey of clinical practice patterns in the management of Graves' disease. Clin Endocrinol (Oxf). 2016;84(1):115-20. doi: 10.1111/cen.12688. [PubMed: 25581877]

3. Ross DS, Burch HB, Cooper DS, Greenlee MC, Laurberg P, Maia AL, et al. 2016 American Thyroid Association Guidelines for diagnosis and management of hyperthyroidism and other causes of thyrotoxicosis. Thyroid. 2016;26(10):1343-421. doi:10.1089/thy.2016.0229. [PubMed: 27521067].

4. Kahaly GJ, Bartalena L, Hegedus L, Leenhardt L, Poppe K, Pearce SH. 2018 European thyroid association guideline for the management of Graves' hyperthyroidism. Eur Thyroid J. 2018;7(4):167-86. doi: 10.1159/000490384. [PubMed: 30283735]. [PubMed Central: PMC6140607].

5. Abraham P, Avenell A, McGeoch SC, Clark LF, Bevan JS. Antithyroid drug regimen for treating Graves' hyperthyroidism. Cochrane Database Syst Rev. 2010;(1). CD003420. doi: 10.1002/14651858.CD003420.pub4. [PubMed: 20091544]. [PubMed Central: PMC6599817]. 
6. Kitahara CM, Berrington de Gonzalez A, Bouville A, Brill AB, Doody MM, Melo DR, et al. Association of radioactive iodine treatment with cancer mortality in patients with hyperthyroidism. JAMA Intern Med. 2019. doi: 10.1001/jamainternmed.2019.0981. [PubMed: 31260066]. [PubMed Central: PMC6604114].

7. Azizi F, Ataie L, Hedayati M, Mehrabi Y, Sheikholeslami F. Effect of longterm continuous methimazole treatment of hyperthyroidism: Comparison with radioiodine. Eur J Endocrinol. 2005;152(5):695-701. doi: 10.1530/eje.1.01904. [PubMed: 15879354].

8. Laurberg P, Berman DC, Andersen S, Bulow Pedersen I. Sustained control of Graves' hyperthyroidism during long-term low-dose antithyroid drug therapy of patients with severe Graves' orbitopathy. Thyroid. 2011;21(9):951-6. doi: 10.1089/thy.2011.0039. [PubMed: 21834677].

9. Orgiazzi J. Should protracted treatment with antithyroid drug (ATD) be considered as a routine strategy in patients with Graves' disease who had a relapse after a first course of ATD? Clin Thyroidol. 2015;27(11):302-5. doi: 10.1089/ct.2015;27.302-305.

10. Villagelin D, Romaldini JH, Santos RB, Milkos AB, Ward LS. Outcomes in relapsed Graves' disease patients following radioiodine or prolonged low dose of methimazole treatment. Thyroid. 2015;25(12):128290. doi: 10.1089/thy.2015.0195. [PubMed: 26414885].

11. Chen DY, Jing J, Schneider PF, Chen TH. Comparison of the longterm efficacy of low dose 131I versus antithyroid drugs in the treatment of hyperthyroidism. Nucl Med Commun. 2009;30(2):160-8. doi: 10.1097/MNM.ob013e3283134d4d. [PubMed: 19194213].

12. Azizi F, Malboosbaf R. Long-term antithyroid drug treatment: A Systematic review and meta-analysis. Thyroid. 2017;27(10):1223-31. doi: 10.1089/thy.2016.0652. [PubMed: 28699478].
13. Azizi F, Malboosbaf R. Safety of long-term antithyroid drug treatment? A systematic review. J Endocrinol Invest. 2019;42(11):1273-83. doi: 10.1007/s40618-019-01054-1. [PubMed: 31134536].

14. Leger J, Gelwane G, Kaguelidou F, Benmerad M, Alberti C; French Childhood Graves' Disease Study Group. Positive impact of long-term antithyroid drug treatment on the outcome of children with Graves' disease: National long-term cohort study. J Clin Endocrinol Metab. 2012;97(1):110-9. doi: 10.1210/jc.2011-1944. [PubMed: 22031519].

15. Sato H, Minagawa M, Sasaki N, Sugihara S, Kazukawa I, Minamitani $\mathrm{K}$, et al. Comparison of methimazole and propylthiouracil in the management of children and adolescents with Graves' disease: Efficacy and adverse reactions during initial treatment and longterm outcome. J Pediatr Endocrinol Metab. 2011;24(5-6):257-63. doi: 10.1515/jpem.2011.194. [PubMed: 21823520].

16. Yasuda K, Miyoshi Y, Tachibana M, Namba N, Miki K, Nakata Y, et al. Relationship between dose of antithyroid drugs and adverse events in pediatric patients with Graves' disease. Clin Pediatr Endocrinol 2017;26(1):1-7. doi: 10.1297/cpe.26.1. [PubMed: 28203042]. [PubMed Central: PMC5295245].

17. Azizi F, Amouzegar A, Tohidi M, Hedayati M, Khalili D, Cheraghi L, et al. Increased remission rates after long-term methimazole therapy in patients with Graves' Disease: Results of a randomized clinical trial Thyroid. 2019;29(9):1192-200. doi: 10.1089/thy.2019.0180. [PubMed: 31310160].

18. Azizi F, Takyar M, Madreseh E, Amouzegar A. Long-term methimazole therapy in juvenile Graves' disease: A randomized trial. Pediatrics. 2019;143(5). doi: 10.1542/peds.2018-3034. [PubMed: 31040197]. 